\title{
CONF-9409153--3
}

UCRL-JC-118666

PREPRINT

\section{Aerogel Commercialization: Technology, Markets and Costs}

\author{
G. Carlson \\ D. Lewis
}

K. McKinley

J. Richardson

T. Tillotson
RECEIVED

NOV $1>1995$

OSTI

This paper was prepared for submittal to the

Proceedings of the 4th International

Symposium on Aerogels (ISA 4)

Berkeley, CA

September 19-21, 1994

October 7, 1994

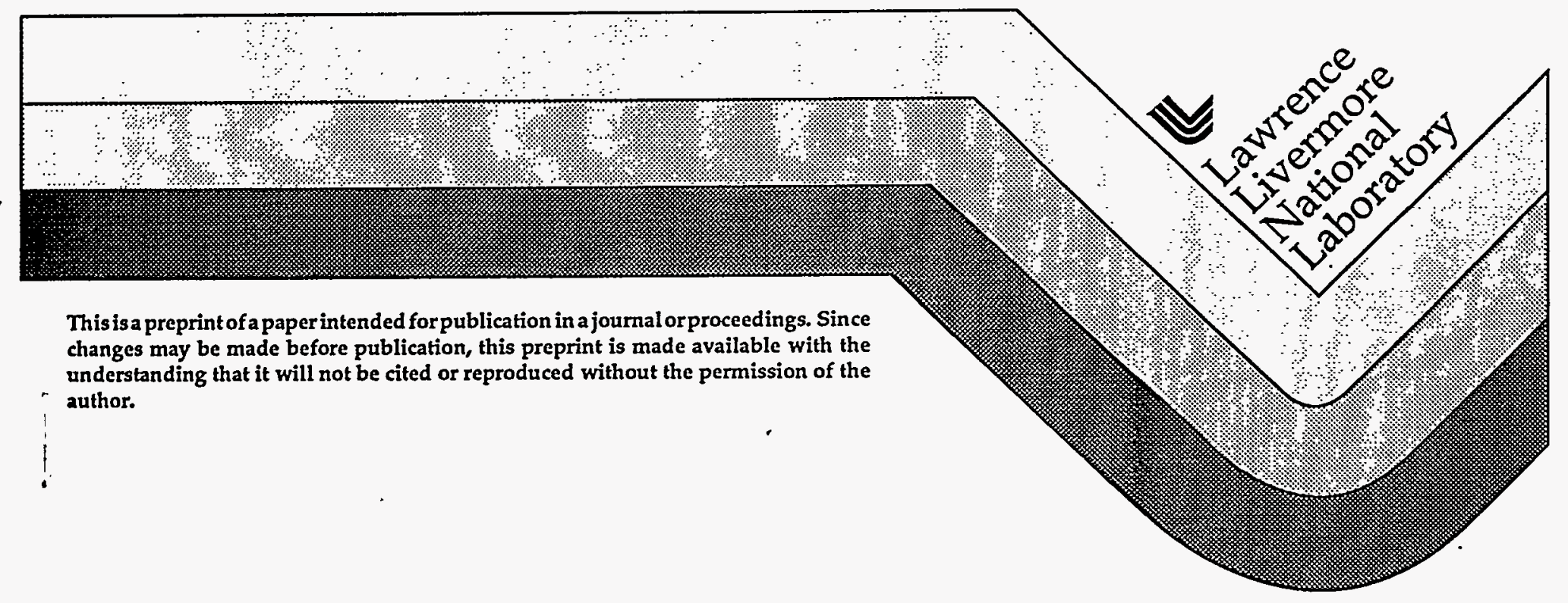




\section{DISCLAIMER}

This document was prepared as an account of work sponsored by an agency of the United States Government. Neither the United States Government nor the University of California nor any of their employees, makes any warranty, express or implied, or assumes any legal liability or responsibility for the accuracy, completeness, or usefulness of any information, apparatus, product, or process disclosed, or represents that its use would not infringe privately owned rights. Reference herein to any specific commercial product, process, or service by trade name, trademark, manufacturer, or otherwise, does not necessarily constitute or imply its endorsement, recommendation, or favoring by the United States Government or the University of California. The views and opinions of authors expressed herein do not necessarily state or reflect those of the United States Government or the University of California, and shall not be used for advertising or product endorsement purposes. 
AEROGEL COMMERCIALIZATION:

TECHNOLOGY, MARKETS AND COSTS

G. CARLSON, D. LEWIS, K. MCKINLEY,

J. RICHARDSON AND T. TILLOTSON

\title{
LAWRENCE LIVERMORE NATIONAL LABORATORY \\ LIVERMORE; CA 94550
}

\author{
SUBMITTED TO THE \\ PROCEEDINGS OF THE 4TH INTERNATIONAL \\ SYMPOSIUM ON AEROGELS (ISA 4)
}

SEPTEMBER 19-21, 1994

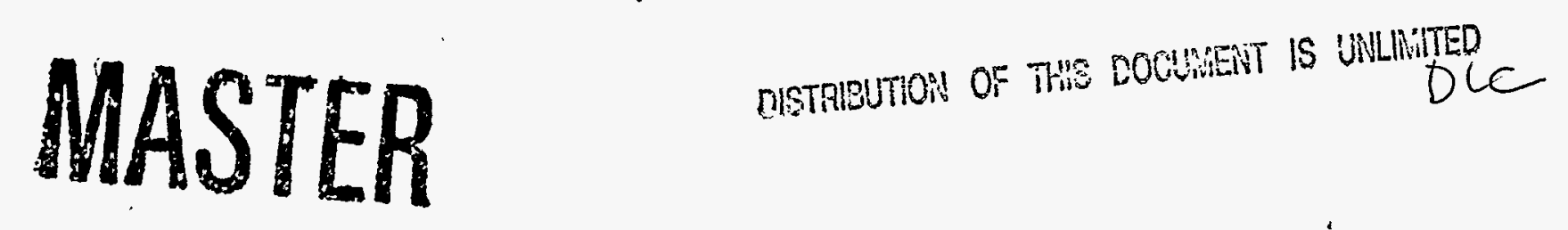




\begin{abstract}
Commercialization of aerogels has been slow due to several factors including cost and manufacturability issues. The technology itself is well enough developed as a result of extensive work over the past decade by an international community of researchers. Several substantial markets appear to exist for aerogels as thermal and sound insulators, if production costs can keep prices in line with competing established materials. We discuss here the elements which we have identified as key cost drivers, and we give a prognosis for the evolution of the technology leading to reduced cost aerogel production.
\end{abstract}

\title{
1. Introduction
}

Aerogels are a class of low density solid foams that are characterized by having open cell structures composed of particles usually less than $10 \mathrm{~nm}$ in diameter with pore sizes usually less than $50 \mathrm{~nm}$ in diameter. Aerogels can be made from many different chemical compositions, exploiting chemistry and processing developed for sol-gel technology and then extended and modified to produce low density materials. Most aerogels are made from silica, but organic aerogels have recently been made as well [1].

Although the potential applications for aerogels are wide ranging and virtually unlimited, they are commercially produced only in Sweden, primarily for use in Cerenkov detectors. Of particular commercial interest is the potential for using aerogels in thermal insulation applications. This application would take advantage of the extremely low thermal conductivity of both inorganic and organic aerogels [2] for use with temperature sensitive products and improved energy efficiency. Additional applications include . catalysts and catalyst supports, gas filters and gas storage materials, conducting and dielectric materials in diverse electronic devices, and as acoustic insulation. However, a 
common hurdle in the commercialization of aerogels for any application is the lack of a material source and uncertainty regarding the expected cost of processed material. An initial economic analysis for the production costs of silica aerogels has been completed [3]. Recently we considered the material and production costs of silica aerogel [4,5]; this paper expands upon that earlier work by extending the work to organic aerogels. The cost analysis is broken down into five different areas: materials, energy, manpower, facility costs, and equipment. It is seen that material costs dominate in all but a few cases.

\section{Calculations}

\subsection{General constraints}

All low density aerogels involve the condensation of a reactive monomer to produce a cross linked gel. For example, tetramethoxysilane (TMOS) first hydrolyzes and then condenses in the presence of acid or base to form a silica gel:

$$
\begin{aligned}
& \mathrm{Si}\left(\mathrm{OCH}_{3}\right)+4 \mathrm{H}_{2} \mathrm{O} \rightarrow \mathrm{Si}(\mathrm{OH})_{4}+4 \mathrm{CH}_{3} \mathrm{OH} \\
& \mathrm{Si}(\mathrm{OH})_{4} \rightarrow \mathrm{SiO}_{2}+2 \mathrm{H}_{2} \mathrm{O}
\end{aligned}
$$

Subsequent supercritical extraction of the solvent in an autoclave results in the formation of the aerogel. Common solvents used in the processing include methanol (critical temperature $=240^{\circ} \mathrm{C}$, critical pressure $=81 \mathrm{bar}$ ) and carbon dioxide (critical temperature $=$ $31^{\circ} \mathrm{C}$, critical pressure $=74 \mathrm{bar}$ ). Much of our analysis included methanol as the solvent with the correspondingly higher energy requirements and implicit equipment costs.

Certain simplifying assumptions were used in the calculations. For this evaluation . we assumed a cylindrically-shaped steel autoclave with an internal.volume, $\mathrm{V}$. The internal diameter, internal height, and wall thickness were all parameters which could be varied. Another parameter related to the autoclave is its volume utility, VU, or packing efficiency. Typically the VU would be $\approx 80 \%$, but this depends on both the desired aerogel 
dimensions and the autoclave dimensions. Finally, it was assumed that the plant operates five days a week, with 22 days per month as the standard, in a batch mode. All produced material was assumed to be usable; as this analysis primarily applies to aerogels for thermal insulation, the small increase in thermal conductivity for powder material (either from crushing monolithic material or through emulsion polymerization to produce microspheres) is probably offset by the higher yield and service life.

\subsection{Materials}

Material costs were based on the largest lot size and hence lowest cost for which a quote could be obtained, usually in excess of $10,000 \mathrm{~kg}$. Table I summarizes the starting material costs which we used.

\begin{tabular}{lc}
$\begin{array}{l}\text { TABLE I. MATERIAL INPUT COSTS } \\
\text { Material }\end{array}$ & \\
\cline { 2 - 2 } & Cost $(\$ / \mathrm{kg})$ \\
Methanol & 0.34 \\
Tetramethoxysilane (TMOS) & 12.63 \\
Tetraethoxysilane (TEOS) & 4.63 \\
Sodium silicate & 0.91 \\
Resorcinol & 6.17 \\
Formaldehyde & 0.33 \\
Phenol & 1.06 \\
Melamine-formaldehyde (R714) & 3.31 \\
Furfural & 1.74
\end{tabular}

The volume of methanol required was calculated by including both the volume utility of the autoclave as well as additional volume needed to produce the desired aerogel density (after correcting for produced water and methanol, in the case of silica aerogel from TMOS, per equations (1) and (2)). Additional required materials were not considered in this analysis (e.g., wash solvents, catalysts, cooling water). 


\subsection{Energy}

Energy costs were expected to be a significant portion of the aerogel production . costs due to the supercritical extraction process and included three different categories: supercritical extraction of methanol, heating of the autoclave steel, and heat losses to the surroundings. The energy required to pass one liter of methanol through the supercritical path is less than $2 \mathrm{MJ}$, with an energy cost of $\$ 0.031 / \mathrm{MJ}$ assumed. To be conservative, $50 \%$ of this value was used when the solvent was changed to carbon dioxide for supercritical extraction of organic aerogels (the higher temperature associated with alcohol precludes its use with the more thermally liable organic materials). The energy required to heat the autoclave was calculated with credit being given for multiple batches and the assumption that the autoclave would not return to room temperature in-between batches. Specifically, it was assumed that if the full heating energy is consumed for one batch per day, only $70 \%$ per batch would be consumed for two batches per day and only $40 \%$ per batch when three batches are produced per day. Finally, energy lost to the surroundings was estimated as a function of surface area and temperature gradient, assuming that the outer case would remain at ambient. Similarly to autoclave heating, if multiple batches were run in a day, it was noted that the autoclave surface temperature would not return to ambient. Consequently, the actual heat loss would be less for multiple batches. The "equivalent" time for calculating heat loss was 14, 16 and 18 hours for 1,2 and 3 batches per day, respectively (i.e., from the standpoint of calculating heat loss this corresponds to 10,8 , and 6 hours per batch for 1,2, and 3 batches per day, respectively, with each batch requiring a base heating time of four hours, although the actual total time per batch would be longer). Although both factors are only crudely estimated by these adjustments, actual 
energy costs due to autoclave heating and losses to the surroundings are small compared to the overall production costs.

\subsection{Manpower}

Three shifts per day were estimated, with a total staff of 10 people divided over the three shifts and total overhead equal to $50 \%$ of wage/salary. Thus, the total weekday costs for the first six-person shift were calculated to be $\$ 1704$, with subsequent two-person shifts being $\$ 511$.

\subsection{Facility costs}

Facility costs were estimated for a light industrial building to be $\$ 1.28 / \mathrm{sq}$. ft with $\$ 300 /$ month utility costs, equivalent to approximately $\$ 1000 /$ month for a 6500 sq. $\mathrm{ft}$ facility. This value was based on actual regional costs.

\subsection{Equipment}

Price quotes for three different cylindrical autoclave systems were obtained, corresponding to $8561,1902 \mathrm{l}$, and $6849 \mathrm{l}$, all with equivalent pressure and temperature control systems. The cost estimate was $\$ 0.8 \mathrm{M}, \$ 1.4 \mathrm{M}$, and $\$ 3.5 \mathrm{M}$, respectively. Amortized over five years with an annual interest rate of $10 \%$ results in daily costs of $\$ 773$, $\$ 1352$, and $\$ 3380$, respectively.

\section{Results}

The information compiled with respect to the five principle variables were incorporated into a spread sheet to facilitate a parameter study process. Plots were generated using the data obtained from the spreadsheet to identify any areas where cost reductions were possible. The principle cost variables investigated were the cost of the starting materials, autoclave size, number of shifts per day, aerogel density, volume utility of the autoclave, and an initial examination of alcohol recycling. Aerogel costs were 
estimated in terms of dollars per board foot (i.e., $30 \times 30 \times 2.5 \mathrm{~cm}$ ); default variables were silica aerogel from TEOS (tetraethoxysilane), the small autoclave, 3 shifts per day, 100 $\mathrm{kg} / \mathrm{m}^{3}$ aerogel density, and $80 \%$ volume utility.

Figure 1 is representative of the cost optimization obtained by this parameter study using TEOS. Increasing the number of shifts was less significant with the larger autoclave, but still resulted in a decrease in aerogel cost of about $2 \%$. The linearity of the aerogel cost with density dramatized the importance of the final product cost on starting materials as opposed to production costs: Significant cost savings of up to $20 \%$ resulted from alcohol recycling, evaluated at $0,50 \%$, and $100 \%$ recycling. However, additional equipment costs necessary to accomplish recycling were not included, thus warranting further analysis. For comparison between different compositions, the following default variables were chosen based on the optimization with TEOS: $100 \mathrm{~kg} / \mathrm{m}^{3}, 3$ shifts per day, the large autoclave, $90 \%$ solvent recycle, and $80 \%$ volume utility.

Selected data sets were evaluated and the distribution of costs plotted in pie charts. The base materials costs were divided into two parts. The inorganic or organic monomer was considered separately and the remaining inputs, alcohol and water, were grouped together. Representative pie charts are shown in Figures 2-3 for two inorganic aerogels . (TMOS and sodium silicate, respectively) and in Figures 4-5 for two organic aerogels (resorcinol-formaldehyde and phenolic-furfural, respectively).

TABLE II summarizes the aerogel cost per board foot with the following default values: $100 \mathrm{~kg} / \mathrm{m}^{3}, 90 \%$ solvent recycle, 3 shifts, large autoclave, $80 \%$ volume utilization, and $50 \%$ energy costs for organic aerogels. 
TABLE II. AEROGEL COSTS

Material

TMOS

TEOS

Sodium silicate

Resorcinol-formaldehyde (RF)

Phenol-formaldehyde (PF)

RF:PF (50:50)

Melamine-formaldehyde

Phenolic-furfural
Aerogel Cost (\$/board foot)

7.91

4.15

0.63

1.34

0.42

0.89

1.14

0.73

The value for phenol formaldehyde is a goal, based on the precursor costs, although to.date under mild conditions a purely phenol-formaldehyde aerogel has not been synthesized.

\section{Discussion}

Aerogels could serve as the enabling material in many new applications (e.g., energy storage, gas filtration, catalyst supports). However, the biggest potential market is probably insulation. Figure 6 depicts the U.S. insulation market in 1991 [6]. Aerogels have the lowest thermal conductivity of any solid material [2] and the material needs less modification and laboratory development to be inserted into an insulation application than many of the other potential applications.

The projected costs for aerogels from Table II were used in conjunction with the thermal conductivities at one atmosphere in air and under vacuum [2] to calculate the projected cost per $\mathrm{R}$ value for aerogel insulations (Figure 7). These values are compared to the cost per $R$ value for current insulation materials. It is seen that aerogels made from the less expensive precursors are expected to be close in price to the currently used foamed 
plastics. The cost estimates for the vacuum values are based solely on the reduction in thermal conductivity and do not include packaging.

Aerogels have some additional benefits compared to current insulation materials: non-CFC or HCFC containing (the current foamed plastics mostly contain various halogenated carbons), non-flammable in the case of inorganic aerogels, and less volume is required because of the higher $\mathrm{R}$ values. Besides price the furfural-derived aerogel has the added benefit of not requiring formaldehyde, hence reducing the hazards and simplifying the process.

Finally, the production costs excluding materials associated with our cost estimate is $\$ 1.25 / \mathrm{kg}$ for the $\mathrm{CO}_{2}$ extraction; this compares favorably with the previous values of. $\$ 0.50$ to $\$ 1.20$ per kg previously estimated [3]. While this economic analysis is only a first level estimate and omits many factors which should be included for a more detailed analysis, it does lead to two conclusions. First, the dominant factor in the cost of aerogel materials is the cost of the starting materials. Thus, the biggest leverage is obtained by laboratory and process work focused on less expensive starting materials. Second, because of their improved insulation properties, projected aerogel materials are surprisingly cost-competitive even now with the higher end of commercial insulation materials. Further development and economic analysis is certainly warranted in order to assess the feasibility of introducing these materials into the market.

\section{Conclusions}

Although only an initial economic analysis, the cost of starting materials has been identified as the major factor in the overall cost of the manufacture of aerogels. Further development in the use of inexpensive precursors will hasten the deployment of aerogels in the commercial marketplace. 
Acknowledgments

Work performed under the auspices of the U.S. Department of Energy by the

Lawrence Livermore National Laboratory under contract number W-7405-ENG-48.

\section{References}

1. R. W. Pekala, "Organic Aerogels from the Polycondensation of Resorcinol with Formaldehyde," J. Mater. Sci. 24 (1989) 3221.

2. L. W. Hrubesh and R. W. Pekala, "Thermal Properties of Organic and Inorganic Aerogels," J. Mater. Res. 9 (1994) 731.

3. M. J. van Bommel and A. B. de Haan, "Drying of Silica Gels with Supercritical Carbon Dioxide", J. Mater. Sci. 29 (1994) 943.

4. D.L. Lewis and G. A. Carlson, "Silica Aerogel Production Costs", UCRL-ID113450 (January, 1993).

5. J. H. Richardson, Proceedings of the Ozone Safe Cooling 1993 Conference, Washington, DC, p. 420-457 (October 18-19, 1993).

6. "Insulation Materials and Markets: Business Research Report B317", E. J. Mundy, The Freedonia Group, Inc., Cleveland, Ohio (June, 1992). 


\section{Figure Captions}

FIGURE 1. Cost optimization for default values of aerogel production with respect to volume utilization of the autoclave.

FIGURE 2. Optimized.relative silica aerogel production costs with respect to 6 analyzed factors using TMOS as the precursor.

FIGURE 3. Relative optimized silica aerogel production costs with respect to 6 analyzed factors using sodium silicate as the precursor.

FIGURE 4. Optimized relative organic aerogel production costs with respect to 6 analyzed factors using resorcinol-formaldehyde as the precursor.

FIGURE 5. Optimized relative organic.aerogel production costs with respect to 6 analyzed factors using phenolic-furfural as the precursor.

FIGURE 6. U.S. insulation demand in 1991 by type.(reprinted with permission from the Freedonia Group).

FIGURE 7. Comparison of insulation costs per $R$ value for current insulation materials and projected costs for aerogel insulation materials: fiberglass (FG), mineral wool (MW), polyurethane foams (U); polystyrene foams (PS), phenolic foams (P), cellulose (CL), aerogels from sodium silicate (Na Si), resorcinol-formaldehyde (RF), phenolformaldehyde ( $\mathrm{PF}$ ), 50:50 resorcinol-formaldehyde to phenol-formaldehyde (RF:PF), melamine-formaldehyde (MF), and phenolic-furfural (FA). 


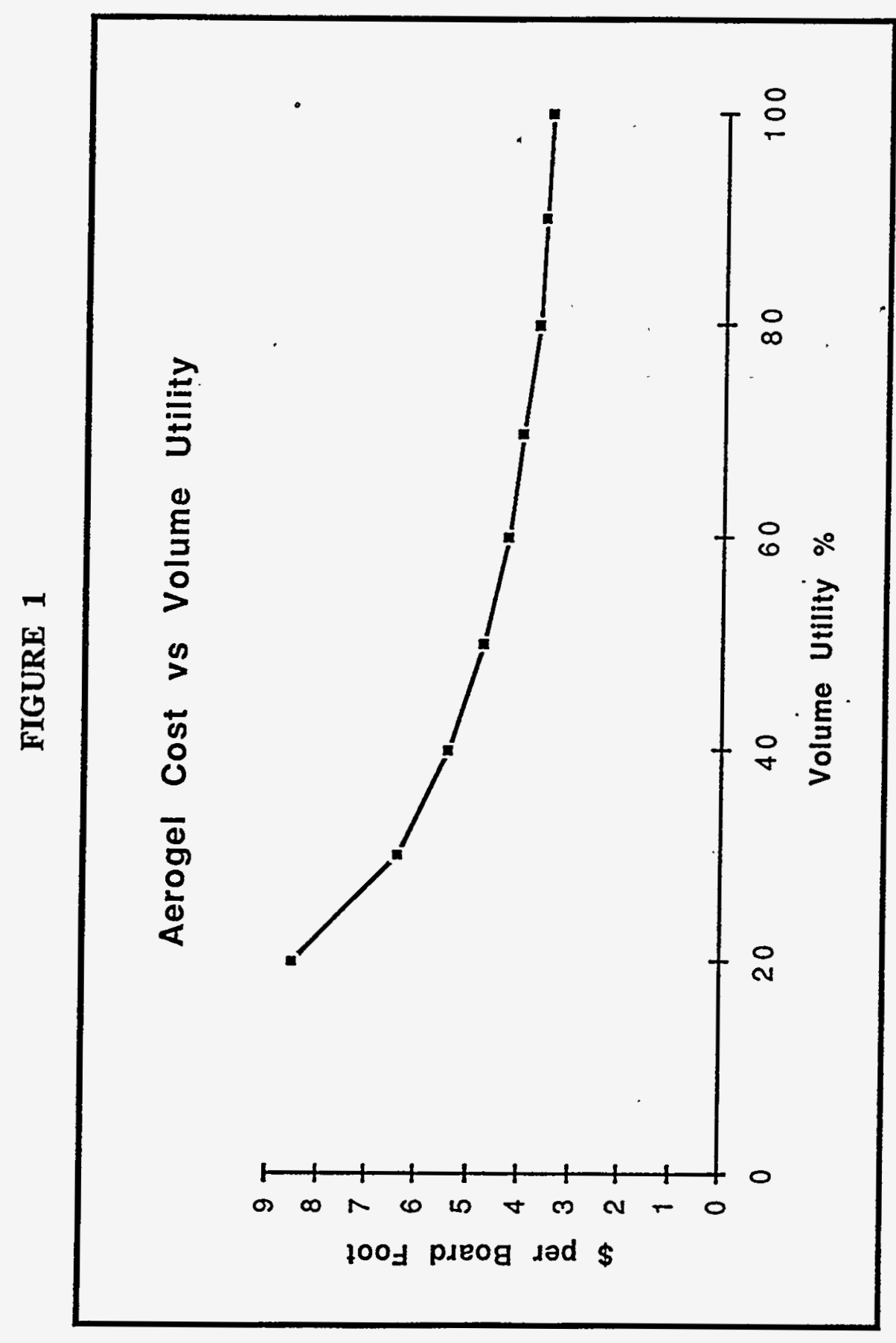

$-11-$ 
FIGURE 2

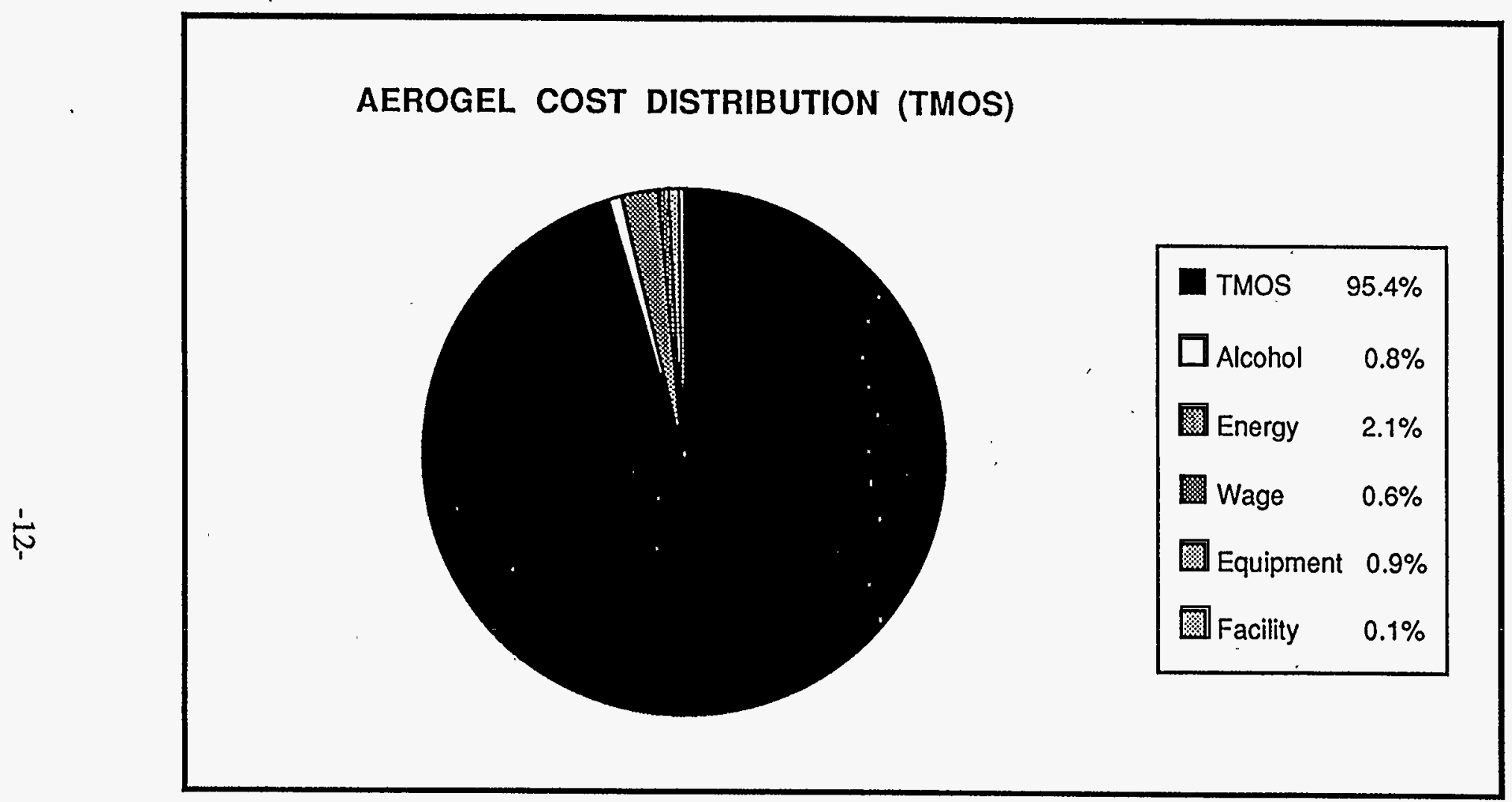




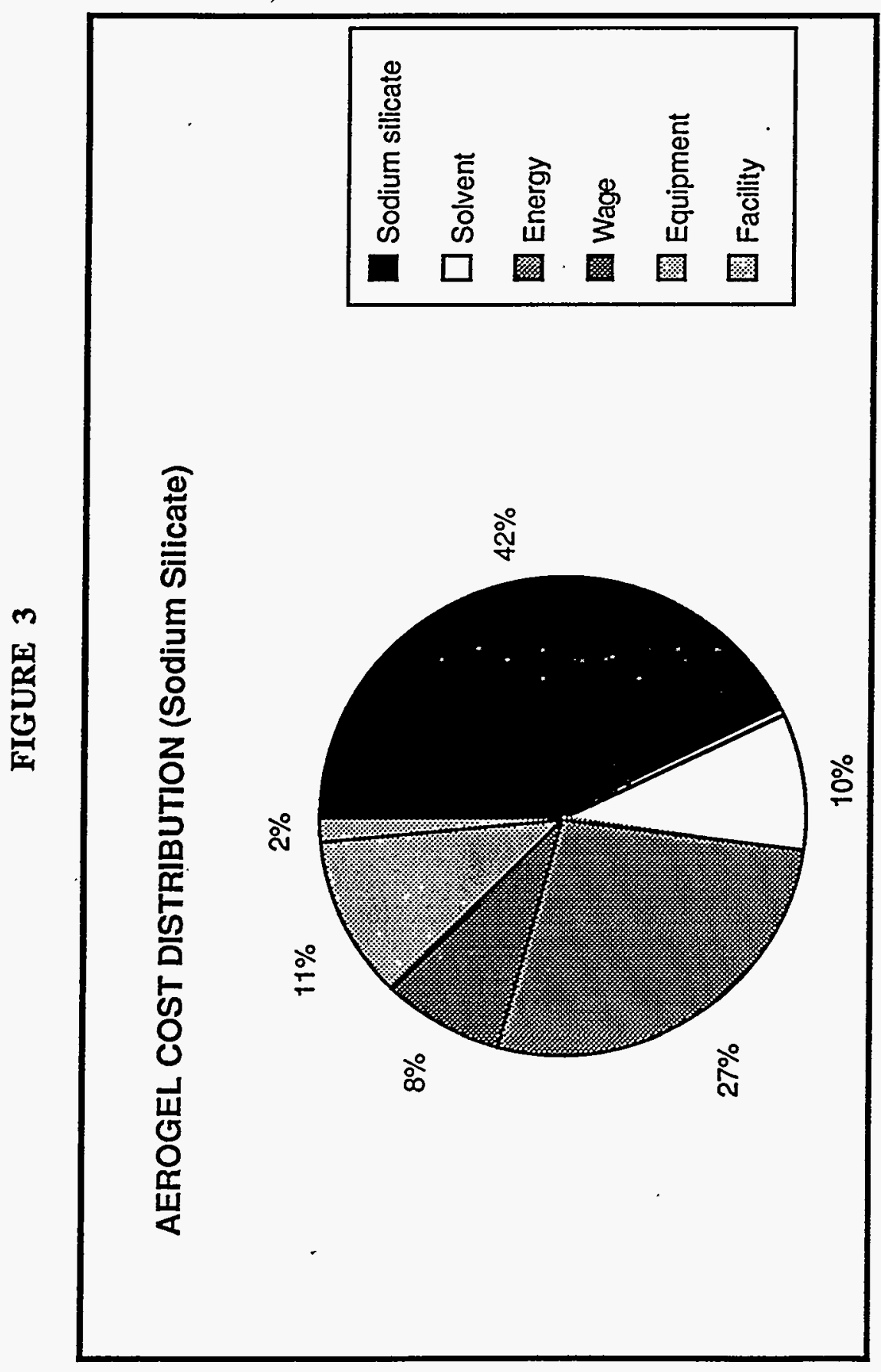




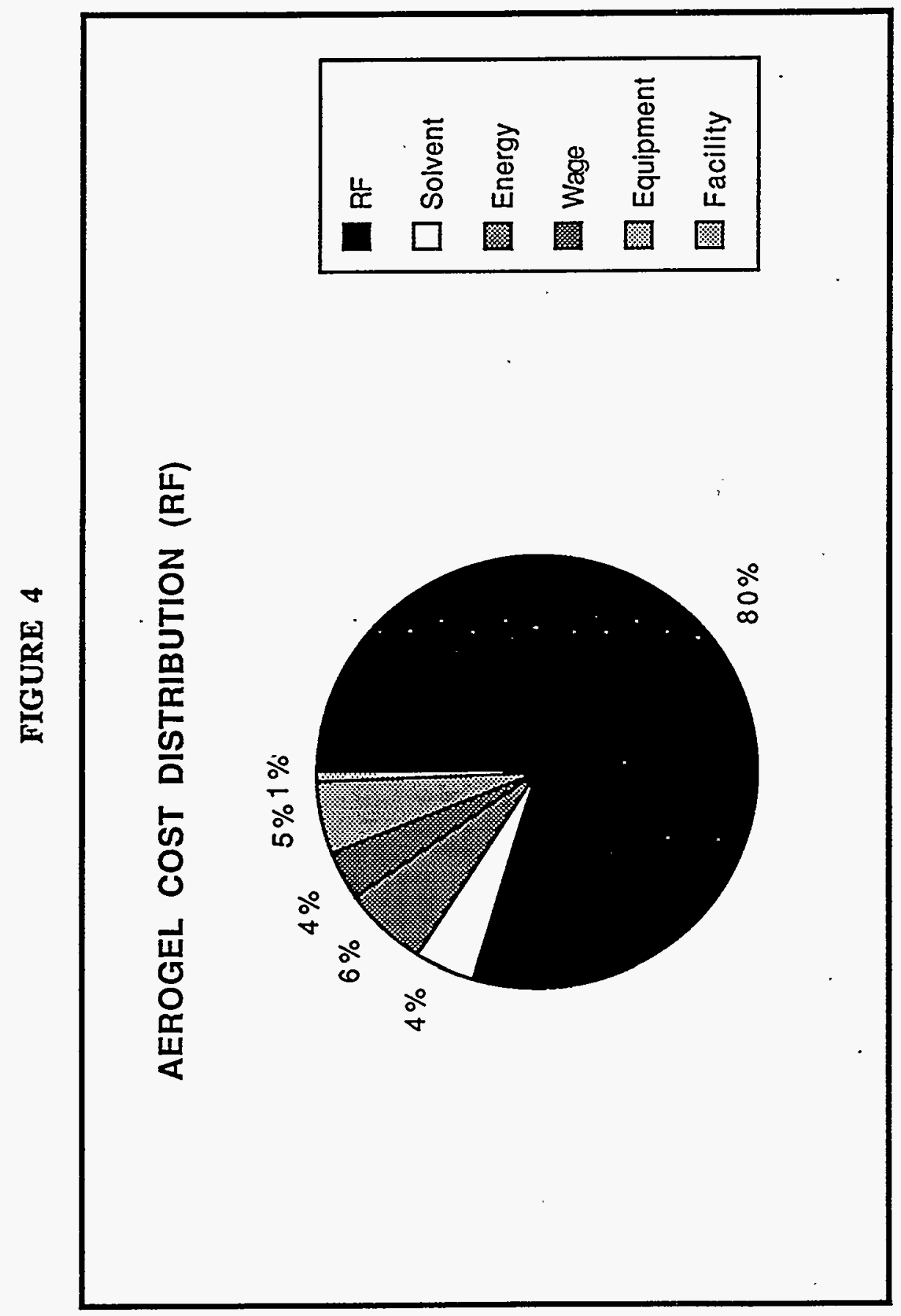


FIGURE 5

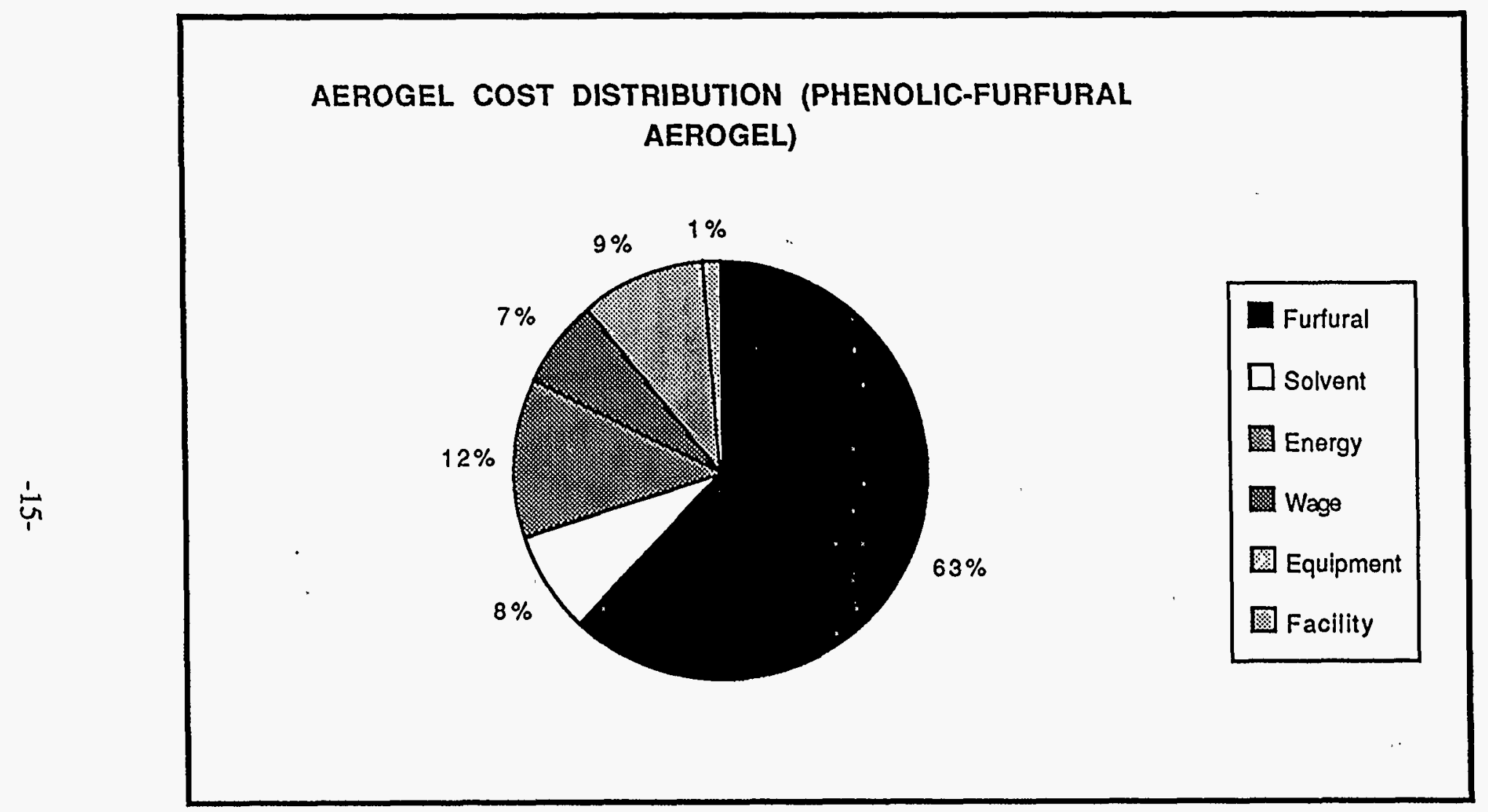


FIGURE 6

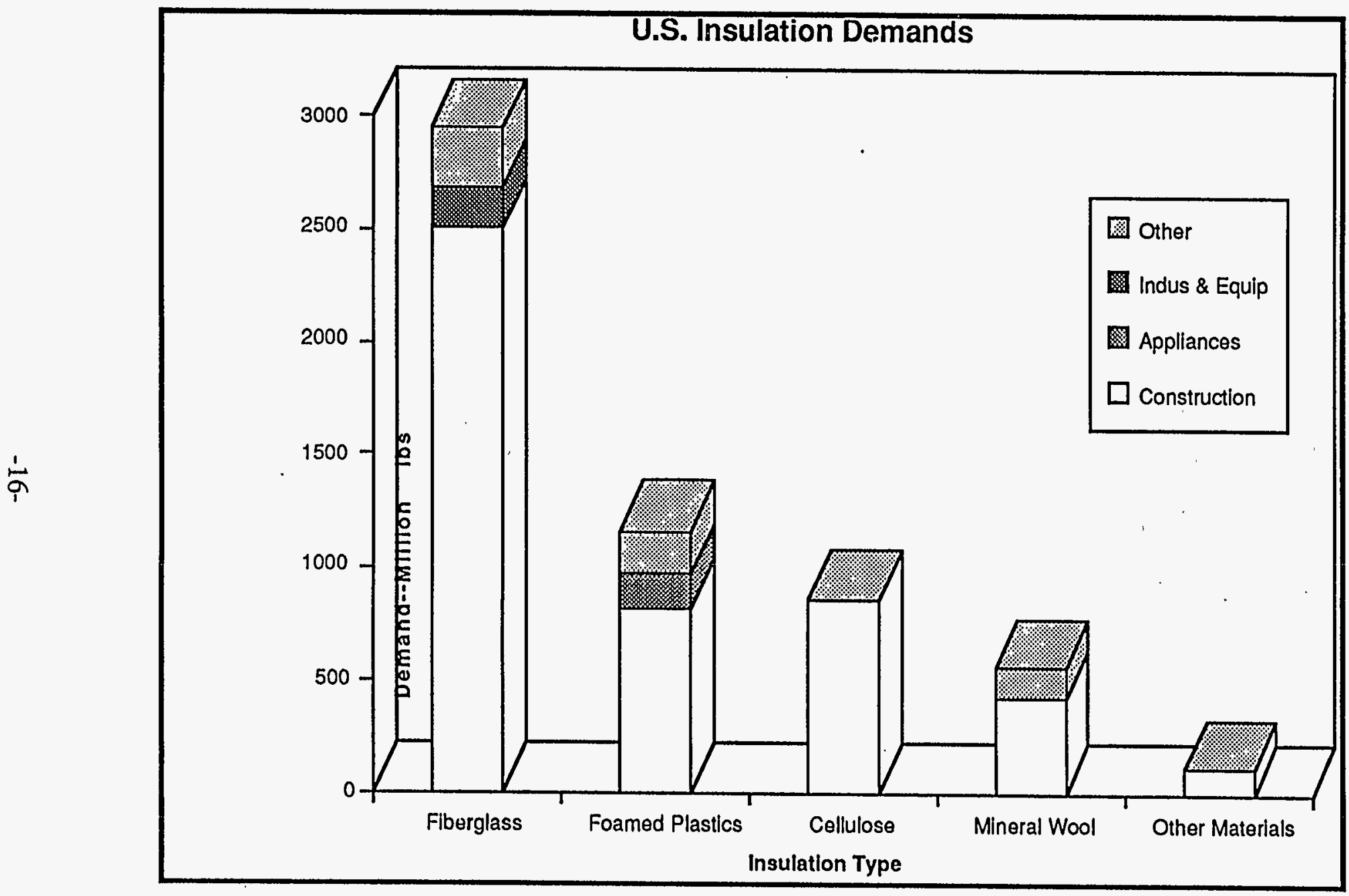




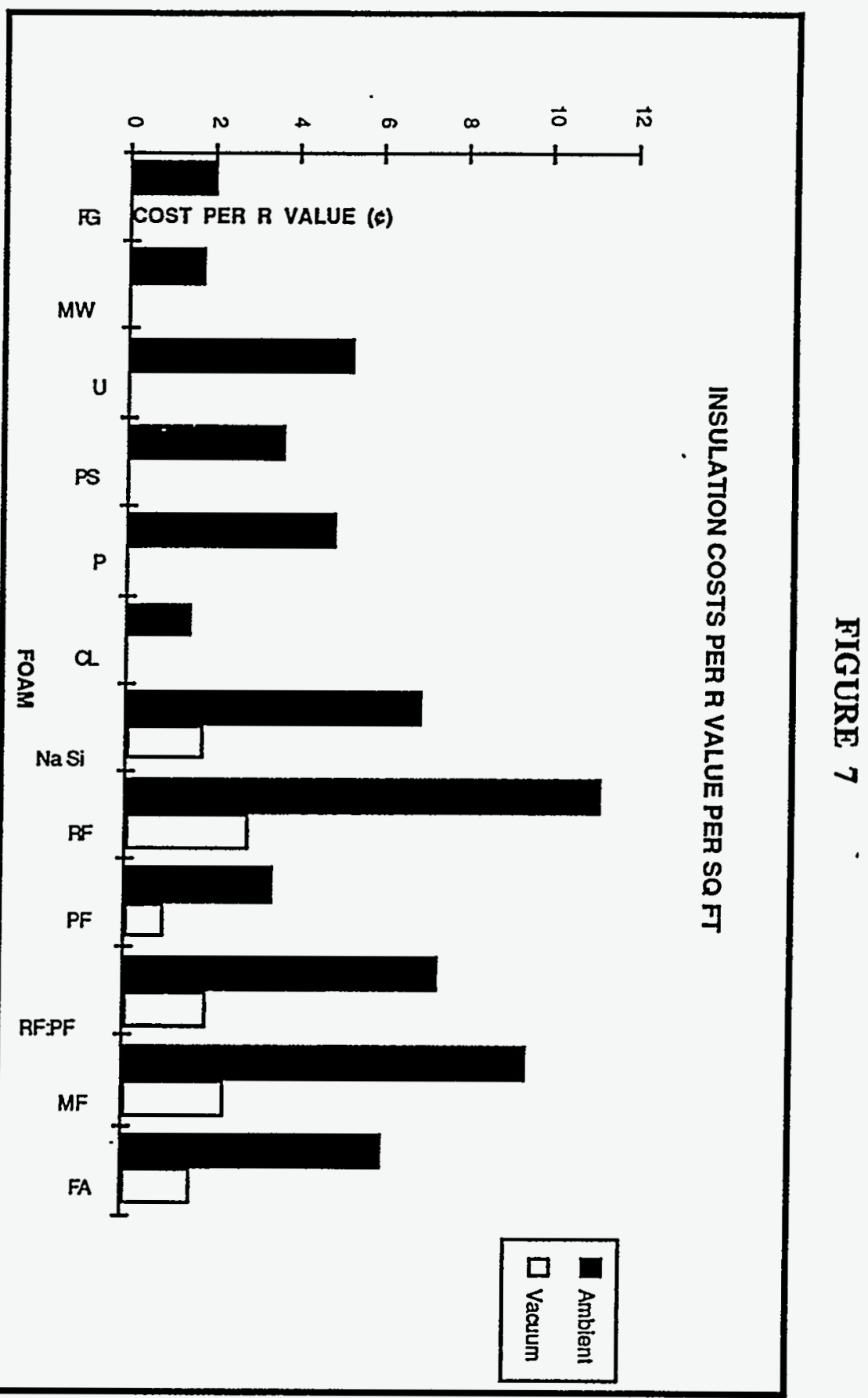



i 

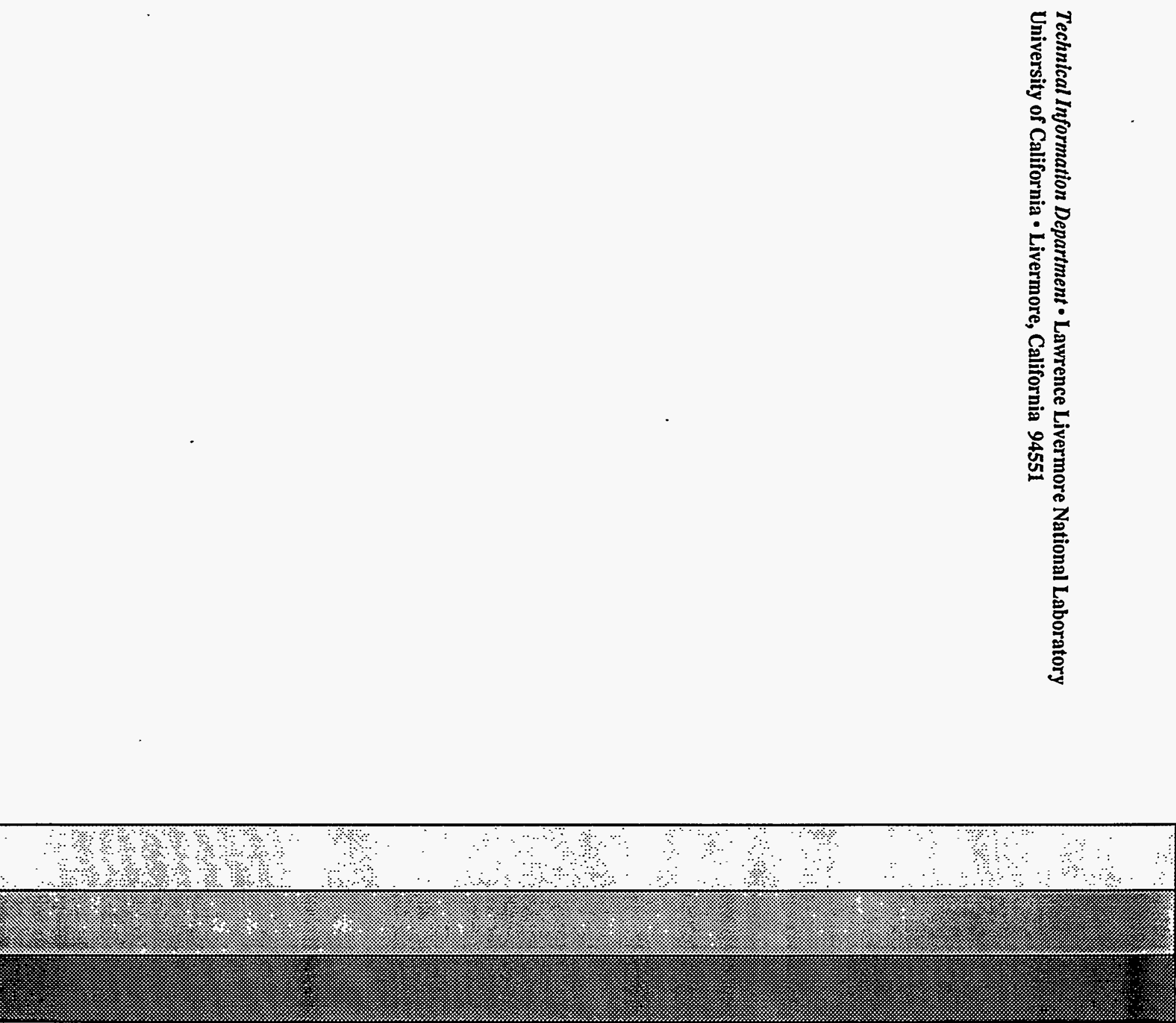